\title{
Estimativas da mortalidade infantil no Brasil, década de oitenta: proposta de procedimento metodológico
}

\author{
Estimates of infant mortality in Brazil in the 80's: a proposal for a \\ methodological procedure
}

Célia Landmann Szwarcwald e Euclides Ayres de Castiho

Depantamento de informaçōes para a Saúde, Fundação Oswaldo Cruz. Rio de Janeiro RJ - Brasil

\begin{abstract}
Propbe-se um procedimento para a estimativa da mortalidade infantil, no Brasil, na década de 80 , baseado apenas na distribuiçăo etárla dos óbltos reg/strados, possibilitando o acompanhamento da evolução deste indicador de forma contínua, ano a ano, em diversas subáreas do País. Anallsa-se a distribuiçăo espaço-temporal das princlpais causas de óbito e discute-se a sensibilidade do risco de morrer entre os menores de um ano face às condiçбes de vida da populaçăo brasilelra, no período de 1979 a 1989.
\end{abstract}

Mortalidade infantil, tendências. Causa da morte. Técnicas de estimação.

\section{Introdução}

As estatísiticas de mortalidade constituem uma das mais tradicionais informações em estudos de populaçāo. No âmbito da saúde pública, as frequiências das causas de morte e a distribuição etária dos óbitos têm sido fontes constantes de análise para caracterizar condiçōes de saúde (Laurenti e col. ${ }^{24}, 1985$ ).

$O$ interesse em expressar quantitativamente diferentes situaçōes de mortalidade através de medidas sintetizadoras tem estimulado, ao longo do tempo, a proposição das chamadas estatísticas de saúde (Hanoluwka ${ }^{21}$, 1987). Neste sentido, o coeficiente de mortalidade infantil exerce papel fundamental. Desde a constatação de declínio acentuado nos países industrializados, é tído como um dos indicadores mais expressivos da situação de saúde e da condição social de uma população (Pollard e col. ${ }^{37}, 1974$ ).

A disponibilidade e a qualidade das estatísticas vitais têm imposto série de restrições para o uso do coeficiente de mortalidade infantil no Brasil (Irwin e Oliveira ${ }^{22}$, 1974; Jorge $^{23}, 1983$ ). Dado pelo número de óbitos em menores de um ano para cada mil nascidos vivos (NV), conforme defínição intenacional, o seu cálculo é problemático em parses onde a cobertura das informações de registro é incompleta.

Diante das limitaçōes das fontes primárias de informações em grande parte dos países subdesenvolvidos, a pesquisa demográfica dedicou-se à formulação de técnicas, ditas de mensuração indireta e baseadas em dados de entrevistas censitárias ou em pesquisas especiais para substituir as estimativas clássicas (United Nations ${ }^{45}, 1990$ ). Entretanto, as estimativas assim obtidas referem-se a intervalos de tempo irregulares, o que constitui sério empecilho para a monitoração da mortalidade.

O caráter de continuidade, singular aos dados de registro, tem encorajado a produção de métodos para estimar indicadores de mortalidade mediante 0 ajuste das estatísticas vitais (Sawyer ${ }^{38}, 1984$ ). Nos últimos trinta anos, vários procedimentos têm sido desenvolvidos baseando-se no simples princípio de que se a taxa de sub-registro de óbitos é aproximadamente constante por idade, a distribuição etária das mortes não é afetada (United Nations ${ }^{44}, 1983$ ).

Com o propósito de caracterizar o comportamento da mortalidade infantil no Brasil, na década 
de 80 , defrontou-se com o problema de estimar este indicador em regiōes com grande precariedade das estatísticas de óbitos. Tentativas de uso das técnicas já existentes não se mostraram satisfatórias, sobretudo pelas restrições impostas pelos modelos nem sempre válidos para os dados brasileiros. Recorreu-se, portanto, ao instrumental matemático e estatístico para propor um procedimento que possibilitasse mensurar a mortalidade infantil de forma contínua, ano a ano, nas diversas subáreas geográficas do território nacional.

O presente trabalho tem o objetivo principal de propor procedimento para estimar a mortalidade infantil no Brasil, na década de 80 , a partir das informaçōes de óbitos registrados. Fundamenta-se em representar a mortalidade proporcional por idade por meio de indicadores invariantes ao subregistro de óbitos.

\section{Metodologia}

O método ora proposto para caracterizar a evoluçāo da mortalidade infantil no Brasil, na década de 80 , foi desenvolvido em duas etapas. Primeiramente, urna aproximaçāo matemática ao modelo geral das Naçōes Unidas (United Nations ${ }^{43}$, 1982) possibilitou a sua utilizacāo para populações com coberturas não completas das estatísticas vitais, permitindo a obtenção das estimativas no ano de 1980 para todas as Unidades da Federação (UF), como apresentado na sessão seguinte.

Na segunda etapa , para mensuração da mortalidade infantil durante a década de 80 sem depender de informaçoeses censitárias, propōe-se procedimento baseado apenas na mortalidade proporcional por idade, fundamentando-se em representar a composição etária dos óbitos por meio de indicadores invariantes ao sub-registro de obitos. Através de uma análise estatística por componentes principais e dos indicadores construídos nas UFs, no triênio 1979-1981, o padrāo etário brasileiro de mortalidade foi expresso por número reduzido de fatores.

As estimativas da mortalidade infantil foram obtidas quantificando-se os desvios entre a mortalidade proporcional por idade de cada UF e o padrão nacional. A relaçāo foi obtida por meio de uma regressão logito-linear tendo como variável resposta os valores estimados pelo modelo da ONU modificado, e como variáveis independentes os "scores" padronizados nos três primeiros componentes principais.

Por meio do método proposto, utilizando-se as "Estatísticas do Registro Civil" (FIBGE ${ }^{\jmath 17}, 1981$,
1983, 1984, 1986, 1988,1989, 1990, 1991), foi possível estimar a mortalidade infantil por grandes regiōes e regiões metropolitanas, no período de 1979 a 1989. A partir das informaçбes do Subsistema de Informaçōes sobre Mortalidade do Ministério da Saúde (SIM/MS) ${ }^{26.34}$ (1982-1985, 1987, 1988, 1991,1992), calculou-se a mortalidade proporcional segundo principais causas* entre os menores de um ano, possibilitando a estimativa de taxas específicas por causas de morte.

\section{Estimatlvas para 1980 pelo Modelo da ONU Modificado}

O modelo geral das Nações Unidas (United Nations $^{43}$, 1982) surgiu da necessidade de se construir tábuas-de-vida especificamente para populações em desenvolvimento. $O$ modelo consiste em expressar as alterações na curva de mortalidade (traduzidas pelos logitos das probabilidades de morte nos grupos etários $0-1,1-4,5-9, \ldots ., 80$ 84) de uma determinada populaçāo em relaçāo a uma curva modelo por meio de uma regressăo linear, resultante de uma análise de componentes principais.

Todavia, embora este modelo tenha inúmeras formas de uso para o ajuste das probalidades de morte e para a estimação de parâmetros demográficos, a sua aplicação direta a dados de óbitos subenumerados resulta em distorçóes relevantes de acordo com a magnitude do sub-registro.

A elaboraçăo de um procedimento denominado de "modelo da ONU modificado - MONUM"** possibilitou a sua utilização para populações com estatísticas de mortalidade incompletas. Sob a hipótese de sub-registro de mortes aproximadamente constante em um certo intervalo etário (e.g. 1-69 anos), a reformulaçāo consiste em ajustar os desvios dos logaritmos das taxas observadas de mortalidade por idade em relação a um padrãomédio através de uma análise de regressão múltipla. As estimativas dos coeficientes do MONUM estabelecem a probalidade de morrer no primeiro ano de vida e o grau de cobertura do sistema de registro.

Para a aplicação do MONUM nas grandes regiōes e UFs, por sexo, em 1980, os dados utilizados sobre população foram os referidos no censo de 1980 (FIBGE ${ }^{চ}$, 1984) e os sobre 6́bitos, pub́licados nas estatísticas de Registro Civil (FIBGE ${ }^{\mathrm{B}}, 1981$ ), à

\footnotetext{
* Excluindo-se os óbitos sem definiçāo da causa bósica. ** Ver descrição sucinta no Anexo.
} 
exceção da Região Norte , para a qual foram usadas as informaçōes do Subsistema de Informaçōes sobre Mortalidade do Ministério da Saúde, por terem se mostrado mais fidedignas (Szwarcwald ${ }^{+}$, 1993). Para o ajuste das curvas brasileiras de mortalidade por idade à regressão descrita pela equação (A5) do Anexo, considerou-se o intervalo etário $[1,69]$ anos e adotou-se o padrão "Chilean", como modelo médio, por ter sido o que demonstrou a melhor aderência ao modelo em todas as regiões estudadas. As probabilidades de morte no primeiro ano para ambos os sexo foram calculadas através dos valores obtidos para o sexo feminino e masculino, supondo-se, como habitual, razão de sexo ao nascimento de 1,05 .

Os resultados obtidos pela aplicação do MONUM às estatísticas de mortalidade regionais evidenciam os contrastes internos (Tabelas 1 e 2). A pior notificação foi obtida para a Regiāo Norte, onde a proporção de óbitos declarados não atingia $50 \%$, em 1980. A Região Nordeste é a que apresentava os maiores níveis de mortalidade infantil, calculada em 122/1.000 NV para ambos os sexos, duas vezes maior que no Centro-Sul. Os achados para a Região Centro-Oeste apontam para altas taxas de sub-registro mas risco de morrer no primeiro ano de vida próximo aos obtidos nas regióes mais desenvolvidas do País.

A mortalidade infantil para o Brasil, 1980, estimada em 83 por $1.000 \mathrm{NV}$, foi calculada como sendo a média ponderada das estimativas regionais, utilizando-se pesos proporcionais ao número corrigido de nascidos vivos* em cada grande região.

Tabela 1 - Estimativas da mortalidade infantil (por 1.000 NV) pelo MONUM, segundo as grandes regiōes $\theta$ sexo. Brasil. 1980.

\begin{tabular}{|c|c|c|c|}
\hline \multirow{2}{*}{ Regiäo } & \multicolumn{3}{|c|}{ Mortalidade Infantil (/1.000 NV) } \\
\hline & Sexo Masculino & Sexo Feminino & Total \\
\hline $\begin{array}{l}\text { Norte } \\
\text { Nordeste } \\
\text { Sudeste } \\
\text { Sul } \\
\text { Centro-Oeste }\end{array}$ & $\begin{array}{r}109,9 \\
129,5 \\
61,8 \\
57,9 \\
70,8\end{array}$ & $\begin{array}{r}99,3 \\
114,1 \\
53,4 \\
50,8 \\
49,3\end{array}$ & $\begin{array}{r}104,7 \\
122,0 \\
57,7 \\
54,4 \\
60,3\end{array}$ \\
\hline Brasil & 89,2 & 77,4 & 83,4 \\
\hline
\end{tabular}

MONUM - Modelo da ONU modificado

* Estimativas através de informaçōes censitários pelo método de Brass' (I975).
Tabela 2 - Estimativas do grau de cobertura $(\%)$ pelo MONUM, segundo as grandes regioes e sexo. Brasil. 1980 .

\begin{tabular}{|c|c|c|c|}
\hline \multirow{2}{*}{ Regiäo } & \multicolumn{3}{|c|}{ Sexo } \\
\hline & Masculino & Feminino & Total \\
\hline Norte & 48,1 & 43,1 & 45,9 \\
\hline Nordeste & 50,2 & 48,0 & 49,2 \\
\hline Sudeste & 98,0 & 94,6 & 96,6 \\
\hline & 93.2 & 87,3 & 90.7 \\
\hline Centro-Oeste & 63,1 & 63,1 & 63,1 \\
\hline Brasil & 72,7 & 68,9 & 71,1 \\
\hline
\end{tabular}

MONUM - Modelo da ONU modificado

Para estimar as probabilidades de morte no primeiro ano de vida nas Unidades da Federação através do MONUM, calculou-se, primeiramente, as taxas médias de mortalidade segundo sexo e idade no período 1979-1981. Optou-se por trabalhar com as médias trienais com base no ano de 1980 , para prover maior estabilidade aos coeficientes. Os resultados segundo Unidades da Federação estão apresentados na Tabela 3.

\section{Modelo Baseado na Mortalidade Proporcional por Idade}

O procedimento proposto, seguindo as idéias de Moraes Ms $^{3959)}$ e Guedes e Guedes ${ }^{20}$ (1973). consiste em aferir níveis de mortalidade por meio da quantificação da curva de mortalidade proporcional por idade. A partir dos pressupostos de que o sub-registro de óbitos é aproximadamente constante segundo a variável idade dentro do intervalo de 1 a 69 anos e que o sub-registro de mortes não varia significativamente por meses de idade dentro do intervalo 0-1 ano, o princípio do método é baseado em expressar o padrâo etário de mortalidade de uma dada população por um conjunto de indicadores que independem da magnitude do subregistro de óbitos.

Fundamentando-se na disponibilidade de informaçōes de óbitos registrados, publicadas regularmente, construíram-se os seguintes indicadores:

i) Para o primeiro ano de vida

$X_{01}=$ proporção de óbitos de 28 a 59 dias em relação ao total de óbitos de menores de um ano.

$X_{02}=$ proporção de óbitos de 60-364 dias em relação ao total de óbitos de menores de um ano. 
Tabela 3 - Estimativas da probabilidade de morrer entre os menores de um ano pelo MONUM, segundo as Unidades da Federaçăo (UFs) e sexo, Brasil, 1980.

\begin{tabular}{lccc}
\hline UFs & Sexo Masc. & Sexo Fem. & $\begin{array}{c}\text { Ambos os } \\
\text { Sexos }\end{array}$ \\
\hline RO+AC+RR+AP & 0,1329 & 0,1095 & 0,1215 \\
AM & 0,0977 & 0,0903 & 0,0941 \\
PA & 0,1064 & 0,0972 & 0,1019 \\
MA & 0,0615 & 0,1089 & 0,0846 \\
PI & 0,0667 & 0,0781 & 0,0723 \\
CE & 0,1506 & 0,1289 & 0,1400 \\
RN & 0,1437 & 0,1069 & 0,1253 \\
PB & 0,1776 & 0,1225 & 0,1507 \\
PE & 0,1598 & 0,1135 & 0,1372 \\
AL & 0,1334 & 0,1216 & 0,1276 \\
SE & 0,1147 & 0,0989 & 0,1070 \\
BA & 0,1174 & 0,1055 & 0,1116 \\
MG & 0,0687 & 0,0579 & 0,0634 \\
ES & 0,0859 & 0,0698 & 0,0780 \\
RJ & 0,0662 & 0,0566 & 0,0615 \\
SP & 0,0518 & 0,0479 & 0,0499 \\
PR & 0,0671 & 0,0521 & 0,0598 \\
SC & 0,0587 & 0,0508 & 0,0548 \\
RS & 0,0485 & 0,0465 & 0,0475 \\
MS & 0,0813 & 0,0573 & 0,0696 \\
MT & 0,0838 & 0,0653 & 0,0748 \\
GO & 0,0640 & 0,0464 & 0,0554 \\
DF & 0,0625 & 0,0419 & 0,0525 \\
\hline
\end{tabular}

MONUM - Modelo da ONU modificado.

ii) Entre 1 e 69 anos

$\mathrm{X}_{\mathrm{j}}=$ proporção de óbitos no grupo etário $\mathrm{I}_{\mathrm{j}}$ em relaçāo ao total de 6́bitos entre 1 e 69 anos, para $j=1,2, \ldots \ldots, 14$ onde $I_{1}=1-4$ anos, $I_{2}=5-9$ anos, ,...., $\mathrm{I}_{14}=65-69$ anos.

Obviamente, de acordo com as suposiçōes iniciais, os indicadores $X_{01}, X_{02}$ e $X_{j}(j=1, \ldots \ldots, 14)$ têm a propriedade de se manter inalterados, qualquer que seja o grau de cobertura dos óbitos.

Com o propósito de expressar a mortaliđade proporcional por id̉ade através de um número reduzido de fatores, realizou-se uma análise estatística de componentes principais (descrita em Green ${ }^{19}, 1978$ ), considerando-se como conjunto de variáveis os logaritmos dos dezesseis incicadores $X_{01}, X_{02}$ e $X_{j}(j=1,2, \ldots 14)$, denotados respectivamente por $\mathrm{L}_{1}, \mathrm{~L}_{2}, \ldots \ldots, \mathrm{L}_{16}$. Calculados para as UFs nos anos de 1979, 1980 e 1981, constituíram uma matriz de 77 observações multivariadas. As fontes de informação foram as Estatísticas do Registro Civil referentes ao triênio 1979-1981 (FIBGE ${ }^{7,910}, 1981,1983$ ).

$\mathrm{Da}$ análise estatística, foram escolhidos três fatores que explicaram cerca de $79 \%$ da variância

* Para o Estado do Amozonas utilizou-se como fonte de informaçöes o SIM/MS. total. A rotaçāo dos eixos pelo método varimax (apresentado em Green ${ }^{19}$, 1978) determinou uma nova configuração da matriz de cargas que facilitou a interpretação do espaço reduzido (Tabela 4). As maiores cargas das variáveis referentes aos obitos na infância (1-4 anos) e no primeiro ano de vida foram encontradas no primeiro componente principal, induzindo a denominálo de "Mortalidade proporcional entre os menores de um ano". Os sinais negativos correspondentes a esses grupos etários indicam correlaçāo inversa com a mortalidade infantil. $O$ segundo componente, apresentando cargas grandes (em valor absoluto) correspondentes a quase todos os grupos etários compreendidos entre 5 e 69 anos, foi chamado de "Mortalidade proporcional entre $5 \mathrm{e}$ 69 anos". Exibindo cargas negativas para as idades mais avançadas e positivas entre 1 e 69 anos, neste eixo, melhores situaçōes de mortalidade sāo traduzidas por coordenadas negativas. $O$ terceiro fator tem o papel de explicar diferenças na mortalidade em adultos jovens. Apresentando as maiores cargas para os grupos 35-39, 40-44 e 3034 anos, foi designado "Mortalidade proporcional em adultos jovens de 30-44 anos".

A situação de cada UF, em relacão ao espaço reduzido, pode ser dimensionada através dos "scores" padronizados obtidos em cada componente principal. Os valores médios resultantes, calculados para as UFs no triênio 1979-1981, foram representados no plano cartesiano formado pelos dois primeiros fatores (Figura 1). Observando o gráfico no sentido do círculo trigonométrico, o

Tabela 4 - Cargas dos três primeiros componentes principais após rotação varimax.

\begin{tabular}{|c|c|c|c|c|}
\hline \multirow{2}{*}{$\begin{array}{l}\text { Faixa } \\
\text { etária }\end{array}$} & \multirow{2}{*}{ Variável } & \multicolumn{3}{|c|}{ Componente } \\
\hline & & 1 & 2 & 3 \\
\hline $\begin{array}{l}28-59 \text { dias } \\
60-364 \text { dias } \\
1-4 \text { anos } \\
5-9 \text { anos } \\
10-14 \text { anos } \\
15-19 \text { anos } \\
20-24 \text { anos } \\
25-29 \text { anos } \\
30-34 \text { anos } \\
35-39 \text { anos } \\
40-44 \text { anos } \\
45-49 \text { anos } \\
50-54 \text { anos } \\
55-59 \text { anos } \\
60-64 \text { anos } \\
65-69 \text { anos }\end{array}$ & $\begin{array}{l}L_{1} \\
L_{2} \\
L_{3} \\
L_{4} \\
L_{5} \\
L_{6} \\
L_{7} \\
L_{3} \\
L_{9} \\
L_{10} \\
L_{11} \\
L_{12} \\
L_{13} \\
L_{14} \\
L_{13} \\
L_{18}\end{array}$ & $\begin{array}{l}-0,6556 \\
-0,8072 \\
-0,8408 \\
-0,4870 \\
-0,3305 \\
0,1576 \\
0,2083 \\
0,1191 \\
-0,0072 \\
0,0541 \\
0,2813 \\
0,6124 \\
0,6753 \\
0,5056 \\
0,3143 \\
0,1598\end{array}$ & $\begin{array}{r}-0,3058 \\
-0,0278 \\
0,3733 \\
0,7694 \\
0,7336 \\
0,8967 \\
0,8676 \\
0,7681 \\
0,6132 \\
0,1333 \\
-0,2198 \\
-0,4755 \\
-0,5889 \\
-0,7673 \\
-0,8977 \\
-0,8673\end{array}$ & $\begin{array}{r}-0,0103 \\
-0,0771 \\
-0,2256 \\
-0,2678 \\
-0,2598 \\
-0,0727 \\
0,1660 \\
0,4868 \\
0,5710 \\
0,8623 \\
0,7658 \\
0,4519 \\
0,1391 \\
0,0607 \\
0,0932 \\
-0,1577\end{array}$ \\
\hline \multicolumn{2}{|c|}{$\begin{array}{l}\text { Proporção da varianncia } \\
\text { total }(\%)\end{array}$} & 21,9 & 41,7 & 14,9 \\
\hline
\end{tabular}


quarto quadrante agrega as unidades com os melhores níveis de mortalidade. Aî localizados estão os Estados das regiöes Sul e Sudeste, destacandose o Rio Grande do Sul seguido de São Paulo e Rio de Janeiro. Opostamente, o aglomerado formado por Paraíba, Ceára, Alagoas, Sergipe, Pernambuco, Rio Grande do Norte e Bahia, no terceiro quadrante, expressa as piores condições de mortalidade infantil. Padrōes intermediários são apresentados para as regioes Norte e Centro-Oeste. Situadas no quadrante esquerdo superior, a primeira assemelha-se ao Nordeste no tocante à mortalidade infantil, enquanto a segunda. localizada à sua direita (com exceção do Mato Grosso), aproxima-se das regiōes mais desenvolvidas. Vale notar a posição do Distrito Federal. Suas coordenadas refletem um bom nível em relação à mortalidade no primeiro ano de vida, mas indicam pequenas proporções de óbitos em idosos, traduzindo a estrutura de população jovem da capital do País, em 1980.

Após a análise redutora do espaço multivariado, os três primeiros componentes principais podem ser intepretados como sendo uma estrutura vetorial capaz de expressar o padrão brasileiro da mortalidade proporcional por idade, no triênio 1979-81. As coordenadas ("scores") obtidas nos três novos fatores, desvios padronizados em relação ao padrão, estabelecem as condições de mortalidade de uma dada população. Devidamente ponderadas e totalizadas em uma medida única dão origem a um indicador do nível de mortalidade da população.

Objetivando encontrar as ponderações dos componentes principais que resultassem na estimativa da mortalidade infantil, recorreu-se a uma regressão múltipla tendo como variável-resposta os logitos das probabilidades de morte no primeiro ano de vida, estimadas em cada UF, no triênio 1979-81, por meio do modelo da ONU modificado (MONUM) e dispostas na Tabela 3. Os "scores" padronizados médios nos três fatores retidos após a rotação dos eixos constituíram os vetores independentes.

As estimativas dos coeficientes da regressão estabeleceram a equação de conversāo dos "scores" nos três eixos principais resultando em um algoritmo simples para a mensuração da mortalidade infantil. Denominado de "MPPI" (modelo a partir da mortalidade proporcional por idade), 0 procedimento consiste em calcular os indicadores $\mathrm{L}_{\mathrm{J}}(\mathrm{j}=1,2, \ldots, 16)$ através das informações de registro de óbitos, conforme definição anterior, e a seguir multiplicá-los pelas ponderaçōes $\mathrm{W}_{\mathrm{j}}$

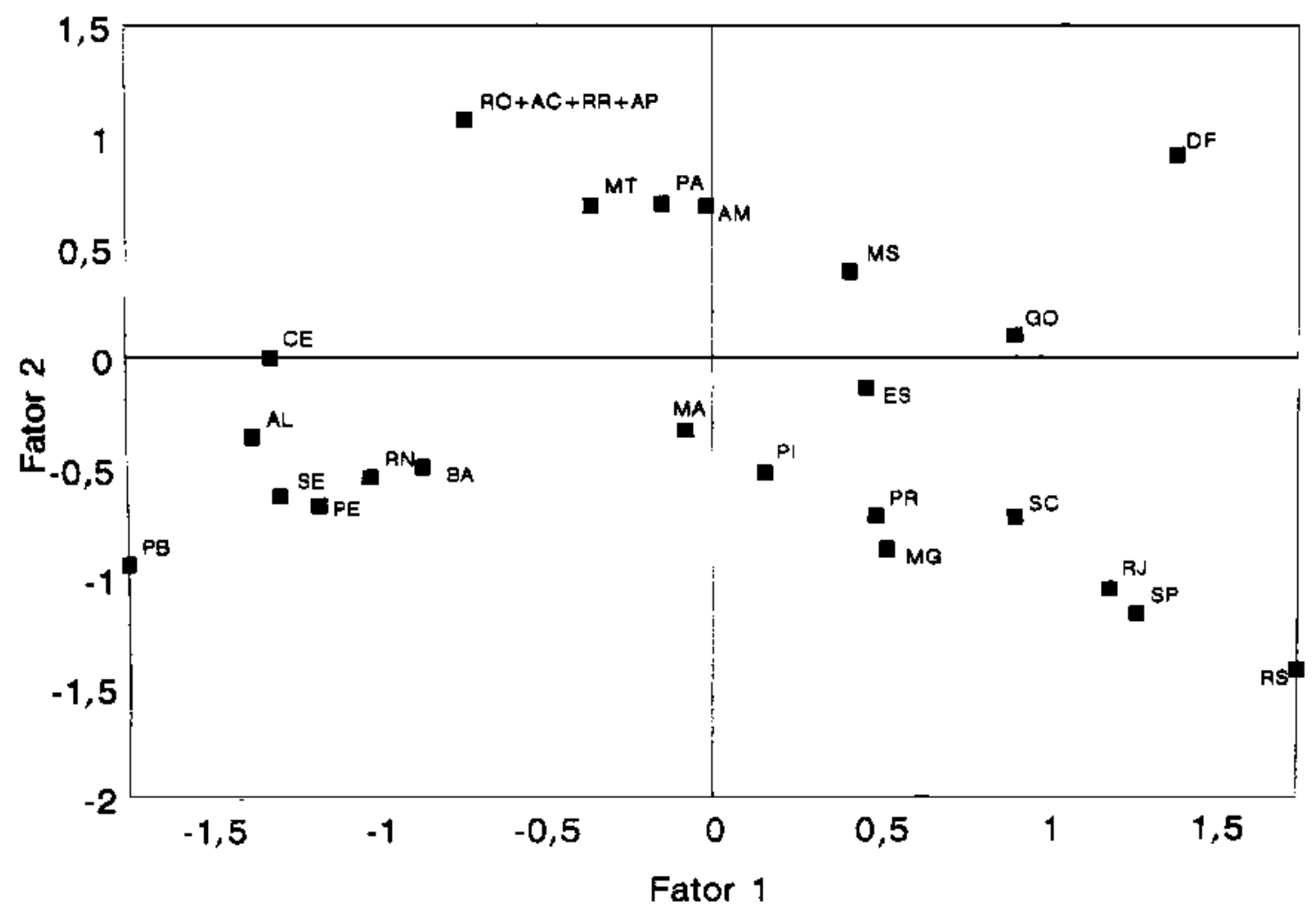

Figura 1 - "Scores" padronizados nos dois primeiros componentes principais. 
$(\mathrm{j}=1,2, \ldots .16)$ dadas na Tabela $5 . \mathrm{O}$ somatório dos valores ponderados, o qual denota-se por $S$, fornece a estimativa de risco de morrer entre os menores de um ano $\left({ }_{1} q_{0}\right)$ :

$$
\hat{q}_{\mathrm{p}}=\frac{\exp [2(-1,1613+S)]}{1+\exp [2(-1,1613+S)]}, \text { onde } S=\sum_{j=1}^{16} W_{j} L_{j} \text {. }
$$

Diferentemente do MONUM, que é um modelos mais geral, o MPPI, proposto com base nas curvas de mortalidade proporcional dos Estados brasileiros, tem aplicação limitada a regiōes do território nacional. Todavia, seu uso no País se justifica. Baseando-se apenas em dados de b́itos publicados regularmente, sem depender de informaçőes censitárias ou de pesquisas especiais, possibilita o acompanhamento anual dos niveis de mortalidade infantil nas diversas subáreas do País, em um período próximo ao ano de 1980. Através do MPPI foi possível estimar a mortalidade infantil por grandes regiős e regioes metropolitanas, de 1979 a 1989.

\section{Mortalldeda Infantll na Década de $\mathbf{8 0}$}

Ao analisar-se o comportamento da mortalidade infantil entre 1979 e 1989 constata-se, de modo geral, que a evolução foi de descenso, reduzindo-se de 90 , em 1979 , a 60 por $1.000 \mathrm{NV}$, em 1989 (Tabela 6). Não obstante a redução, quando comparado a outros países, o Brasil mostrou ritmo lento de declive, e o valor de 60 por

Tabela 5 - Valores da constante $W_{0}$ e das ponderaçoes $W(0=1, \ldots ., 16)$ para estlmativas da mortalidade infantll pelo MPPI.

\begin{tabular}{|c|c|c|c|}
\hline \multirow{2}{*}{$\begin{array}{l}\text { Faixa } \\
\text { etárła }\end{array}$} & Variável & Poderaça & Estimative \\
\hline & Constante & Wo & $-1,1613$ \\
\hline $\begin{array}{l}28-59 \text { dias } \\
60-364 \text { dlas } \\
1-4 \text { anos } \\
5-9 \text { anos } \\
10-14 \text { anos } \\
15-19 \text { anos } \\
20-24 \text { anos } \\
25-29 \text { anos } \\
30-34 \text { anos } \\
35-39 \text { anos } \\
40-44 \text { anos } \\
45-49 \text { anos } \\
50-54 \text { anos } \\
55-59 \text { anos } \\
60-64 \text { anos } \\
65-69 \text { anos }\end{array}$ & $\begin{array}{l}L_{1} \\
L_{2} \\
L_{3} \\
L_{1} \\
L_{0} \\
L_{7} \\
L_{0} \\
L_{10} \\
L_{11} \\
L_{12} \\
L_{13} \\
L_{14} \\
L_{15} \\
L_{10}\end{array}$ & $\begin{array}{l}W_{1} \\
W_{2} \\
W_{3} \\
W_{1} \\
W_{6} \\
W_{6} \\
W_{7} \\
W_{0} \\
W_{0} \\
W_{10} \\
W_{11} \\
W_{12} \\
W_{13} \\
W_{14} \\
W_{15} \\
W_{10}\end{array}$ & $\begin{array}{r}0,3022 \\
0,3373 \\
0,0982 \\
0,0408 \\
0,0176 \\
-0,1035 \\
-0,0976 \\
-0,0252 \\
0,0468 \\
0,1394 \\
0,0326 \\
-0,1339 \\
-0,2232 \\
-0,1123 \\
-0,0269 \\
-0,0147\end{array}$ \\
\hline
\end{tabular}

MPPI - Modelo a partir da mortalidade proporcional por idade.
$1.000 \mathrm{NV}$, em 1989 , representava nível bastante elevado, não só em relação às sociedades desenvolvidas mas também em relação à população latino-americana. Segundo dados do Banco Mundial' (1991), entre 1965 e 1989 a velocidade de decréscimo foi inferior a de vários países vizinhos com renda per capita mais baixa e menores taxas de crescimento econômico. Percebe-se que a série temporal descrita pela mortalidade infantil entre 1979 e 1989 nāo representa um processo uniforme de declive. Nos três primeiros anos há um decréscimo em continuidade à evoluçāo da década de 70 . Contudo, entre 1982 e 1984 ocorre interrupção na tendência de queda com picos de aumento em quase todas as regióes. Ao ano de 1985 corresponde a maior variação de descenso, seguida, porém, de novos acréscimos em 1986.

Compatíveis com os contrastantes contextos socioeconômicos, as disparidades regionais foram acentuadas. A estagnação econômica e a precariedade das condiçōes de vida no Nordeste se traduzem pela persistência de taxas ainda muito elevadas. Enquanto as regiōes mais desenvolvidas apresentavam um índice médio de aproximadamente 50 por $1.000 \mathrm{NV}$, no período de 1979 a 1989, o Nordeste ultrapassava a taxa média de 100 por 1.000 NV (Tabela 6). Apesar do declínio ter alcançado todas as regiões, a tendência da evolução temporal também demonstrou maior fragilidade nas áreas menos favorecidas. Foram o Nordeste e o Norte as que apresentaram as menores taxas de descenso, de $3 \%$ ao ano, enquanto a taxa de variação média para as outras regiōes do País foi de $5 \%$ ao ano.

Observando-se o comportamento da mortalidade infantil nas regiões metropolitanas, foram obtidos, basicamente, os mesmos resultados (Tabela 7). Entretanto, as variaçoes, ora de aumento ora de redução, são bem mais acentuadas. As séries temporais são marcadas por picos agudos entre 1982 e 1984 em todas as metrópoles, à exceção de Belo Horizonte que não apresentou alterações na tendência.

\section{Principais Causas de Morte}

Entre os óbitos em menores de um ano, no Brasil, destacam-se as afecções originadas no período perinatal, as doenças infecciosas intestinais e as infecçōes respiratórias agudas como principais causas de mortalidade. Seguidos pelas deficiências nutricionais e pelas anomalias congênitas, estes fatores explicam quase a totalidade das mortes no primeiro ano de vida (Tabela 8 ). 
Tabela 6 - Estimativas da mortalidade infantil (/1.000 NV) pelo MPPl, segundo as grandes regizes. Brasil, $1979-1989$.

\begin{tabular}{|c|c|c|c|c|c|c|c|c|c|c|c|}
\hline Regiáo & 1979 & 1980 & 1981 & 1982 & 1983 & 1984 & 1985 & 1986 & 1987 & 1988 & 1989 \\
\hline $\begin{array}{l}\text { Norte } \\
\text { Nordeste } \\
\text { Sudeste } \\
\text { Sul } \\
\text { Centro-Oeste }\end{array}$ & $\begin{array}{r}104^{(2)} \\
129 \\
62 \\
65 \\
74\end{array}$ & $\begin{array}{r}99^{(2)} \\
124 \\
58 \\
60 \\
68\end{array}$ & $\begin{array}{r}93^{(2)} \\
115 \\
51 \\
52 \\
57\end{array}$ & $\begin{array}{r}84 \\
108 \\
53 \\
48 \\
61\end{array}$ & $\begin{array}{r}89 \\
408 \\
48 \\
49 \\
60\end{array}$ & $\begin{array}{r}95 \\
113 \\
50 \\
50 \\
53\end{array}$ & $\begin{array}{r}82 \\
101 \\
43 \\
44 \\
48\end{array}$ & $\begin{array}{r}88 \\
103 \\
42 \\
44 \\
50\end{array}$ & $\begin{array}{r}82 \\
100 \\
38 \\
41 \\
49\end{array}$ & $\begin{array}{l}81 \\
97 \\
39 \\
40 \\
44\end{array}$ & $\begin{array}{l}73 \\
89 \\
37 \\
40 \\
43\end{array}$ \\
\hline Brasil & 90 & 85 & 77 & 75 & 73 & 76 & 67 & 68 & 65 & 64 & 60 \\
\hline
\end{tabular}

Fonte: (1) - FIBGE’17 1981; 1983; 1984; 1986; $1988-1991$.

$$
\text { (2) - Ministério da Saúde as as (1982-1984) }
$$

MPPI - Modelo a partir de mortalidade proporcional por idade.

Tabela 7 - Estimativas da mortalidade infantil (11.000 NV) pelo MPPI, segundo as regióes metropolitanas. Brasil, 1979-1989.

\begin{tabular}{|c|c|c|c|c|c|c|c|c|c|c|c|}
\hline $\begin{array}{l}\text { Regiåo } \\
\text { Metropolitana }\end{array}$ & 1979 & 1980 & 1981 & 1982 & 1983 & 1984 & 1985 & 1986 & 1987 & 1988 & 1989 \\
\hline $\begin{array}{l}\text { Belém } \\
\text { Fortaleza } \\
\text { Recife } \\
\text { Salvador } \\
\text { Belo Horizonte } \\
\text { Rio de Janeiro } \\
\text { Sáo Paulo } \\
\text { Curltiba } \\
\text { Porto Alegre }\end{array}$ & $\begin{array}{r}90 \\
134 \\
99 \\
120 \\
77 \\
59 \\
55 \\
68 \\
44\end{array}$ & $\begin{array}{r}73 \\
118 \\
90 \\
113 \\
70 \\
50 \\
51 \\
68 \\
41\end{array}$ & $\begin{array}{r}71 \\
119 \\
78 \\
108 \\
61 \\
46 \\
49 \\
57 \\
34\end{array}$ & $\begin{array}{r}50 \\
117 \\
79 \\
99 \\
61 \\
49 \\
49 \\
53 \\
35\end{array}$ & $\begin{array}{r}54 \\
121 \\
67 \\
105 \\
53 \\
45 \\
39 \\
51 \\
38\end{array}$ & $\begin{array}{r}66 \\
124 \\
76 \\
98 \\
47 \\
48 \\
53 \\
63 \\
45\end{array}$ & $\begin{array}{r}59 \\
104 \\
65 \\
99 \\
50 \\
39 \\
37 \\
55 \\
35\end{array}$ & $\begin{array}{r}65 \\
105 \\
73 \\
92 \\
45 \\
39 \\
37 \\
51 \\
35\end{array}$ & $\begin{array}{l}55 \\
98 \\
60 \\
92 \\
42 \\
37 \\
31 \\
46 \\
38\end{array}$ & $\begin{array}{l}53 \\
85 \\
68 \\
87 \\
46 \\
39 \\
34 \\
43 \\
36\end{array}$ & $\begin{array}{l}53 \\
80 \\
57 \\
83 \\
40 \\
37 \\
34 \\
42 \\
31\end{array}$ \\
\hline
\end{tabular}

Fonte: $\quad$ FIBGE $^{3.17} 1981 ; 1983 ; 1984 ; 1986 ; 1988-1991$.

MPPI - Modelo a partir de mortalidade proporcional por idade.

Expressando uma vez mais a situação deficiente de saneamento, de nutriçāo, de moradia, de educação e de saúde em grande parte do território brasileiro, em 1987, as diarréias ainda explicavam mais de $25 \%$ da mortes com causa definida nas regiōes ao norte do País. $O$ percentual aparentemente pequeno atribuído às deficiências nutricionais traduz apenas a subnotificação da desnutrição como causa de morte, provavelmente, porque as doenças associadas a ela săo priorizadas pelos médicos ao atestarem os 6́bitos (Carvalho', 1986).

Caracterizando a precariedade da assistência médica, chama a atencão o elevado percentual de óbitos em que não foi possível definir a causa da morte (Tabela 8). Na Regiảo Nordeste, a proporçāo de obitos classificados na categoria "sinais, sintomas e afecçôes mal definidas", em 1987, atingia 45\%.

A queda da mortalidade infantil verificada na década de 80 pode ser atribuída em grande parte à redução dos 6́bitos por doenças infecciosas intestinais. A implementacão do programa de reidratacão oral, a retomada da prática do aleitamento materno e a expansão da rede de saneamento contribuíram, certamente, para o declínio expressivo da taxa por diarréias, que decresceu à razão de $9 \%$ ao ano entre
Tabela $B$ - Mortalidade proporcional (\%) entre os menores de um ano, segundo principais causas e grandes regióes. Brasil, 1987.

Regixo

Com Definiçáo da

Causa Básica

N. NE. SE. S. CO.

$\begin{array}{lllllll}\text { D. Infecciosas } \quad 28,4 & 26,6 & 11,2 & 11,6 & 12,9 & 16,8\end{array}$

intestinais

\begin{tabular}{lrrrrrr}
$\begin{array}{l}\text { Deficléncias } \\
\text { nutricionais }\end{array}$ & 2,8 & 5,1 & 4,7 & 4,2 & 4,5 & 4,6 \\
Pneumonia & 9,6 & 8,7 & 6,6 & 10,6 & 10,0 & 10,7 \\
$\begin{array}{l}\text { Anomalias } \\
\text { congônitas }\end{array}$ & 5,3 & 3,9 & 8,3 & 12,2 & 6,7 & 7,4 \\
Causas perin. & 44,4 & 43,8 & 51,4 & 48,2 & 49,2 & 48,3 \\
Outras causas & 9,5 & 11,9 & 17,8 & 13,2 & 14,7 & 12,2 \\
\hline
\end{tabular}

Sem Definiçăo da

$\begin{array}{lllllll}\text { Causa Básica } \quad 23,8 & 45,4 & 5,6 & 11,1 & 11,5 & 22,9\end{array}$

Fonte: Ministério da Saúde ${ }^{34}$ (1992).

N. $=$ Norte

NE. - Nordeste $\quad$ S. $=$ Sul

$\mathrm{SE} .=$ Sudeste $\quad \mathrm{CO} .=$ Centro Oeste 
1979 e 1989. No entanto, irregularidades no comportamento das taxas por diarréia e deficiência nutricionais, encontradas persistentemente em todas as grandes regiōes entre 1982 e 1984, merecem contemplação (Figura 2). Ao serem comparados à invariância da mortalidade infantil por anomalias congênitas, durante todo o período analisado, os agravos da mortalidade infantil por doenças associadas à subnutrição nos momentos de crise constituem-se em evidências empíricas do paralelismo já sobejamente reconhecido entre a conjuntura nutricional e as condiçōes de saúde da populaçāo.

\section{Comentários Finais}

Na década de 80, particularmente nos anos iniciais, o Brasil enfrentou uma fase de grave recessão econômica, com taxas de variações negativas no Produto Intemo Bruto (PIB) per capita, depois de duas décadas de crescimento contínuo. Embora tenha havido certa recuperacão econômica a partir de 1985 , o nível de crescimento anual do PIB caiu de $9 \%$, no período $1965-80$, para 3\%, entre 1980 e 1989 (Banco

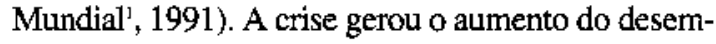
prego e a contenção de investimentos em políticas sociais que acabaram por demonstrar influências negativas nos padrões de saúde da população.

A continuidade da tendência declinante da mortalidade infantil nos primeiros anos da década de 80 , apontada por métodos indiretos de esti- mação através dos dados do censo de 1980 e da PNAD de 1984 (Simões e Oliveira ${ }^{40}, 1986$ ), fez com que se acreditasse, a princípio, na falta de sensibilidade deste coeficiente para indicar uma deterioracão da qualidade de vida neste período (Giraldelli e Fernandes ${ }^{18}$, 1986).

Investigando as informações anuais do Subsistema de Mortalidade do Ministério da Saúde, Becker e Lechtig ${ }^{2}$ (1986) foram os primeiros a detectar acréscimos em 1983 e 1984, sobretudo nas regiōes Norte e Nordeste. Trabalhos posteriores reafirmaram a importância do acompanhamento anual da mortalidade infantil, indicando interrupções no processo de queda em diferentes áreas do País (Castilho e Szwarcwald", 1986; Macedo $^{25}$; Oliveira $^{36}, 1989$; Simões ${ }^{39}$, 1989; Szwarcwald e $\mathrm{col}^{42}, 1989$ ). Nos estudos desta natureza, as maiores dificuldades residem justamente em obter estimativas fidedignas da mortalidade infantil em regiões do País onde ainda há enorme precariedade nos sistemas de informaçóes registradas ern cartório.

O procedimento aqui utilizado visou, sobretudo, o aproveitamento do caráter de continuidade dos dados de registro, buscando retirar deles as informaçōes que, apesar das deficiências do sistema, pudessem expressar as distintas situaçōes de mortalidade infantil encontradas no Brasil, nos anos 80 . Sumarizadas em uma medida única por meio de procedimentos estatísticos multivariados, as estimativas resultantes foram consideradas bastante satisfatórias se comparadas às obtidas por outras técnicas

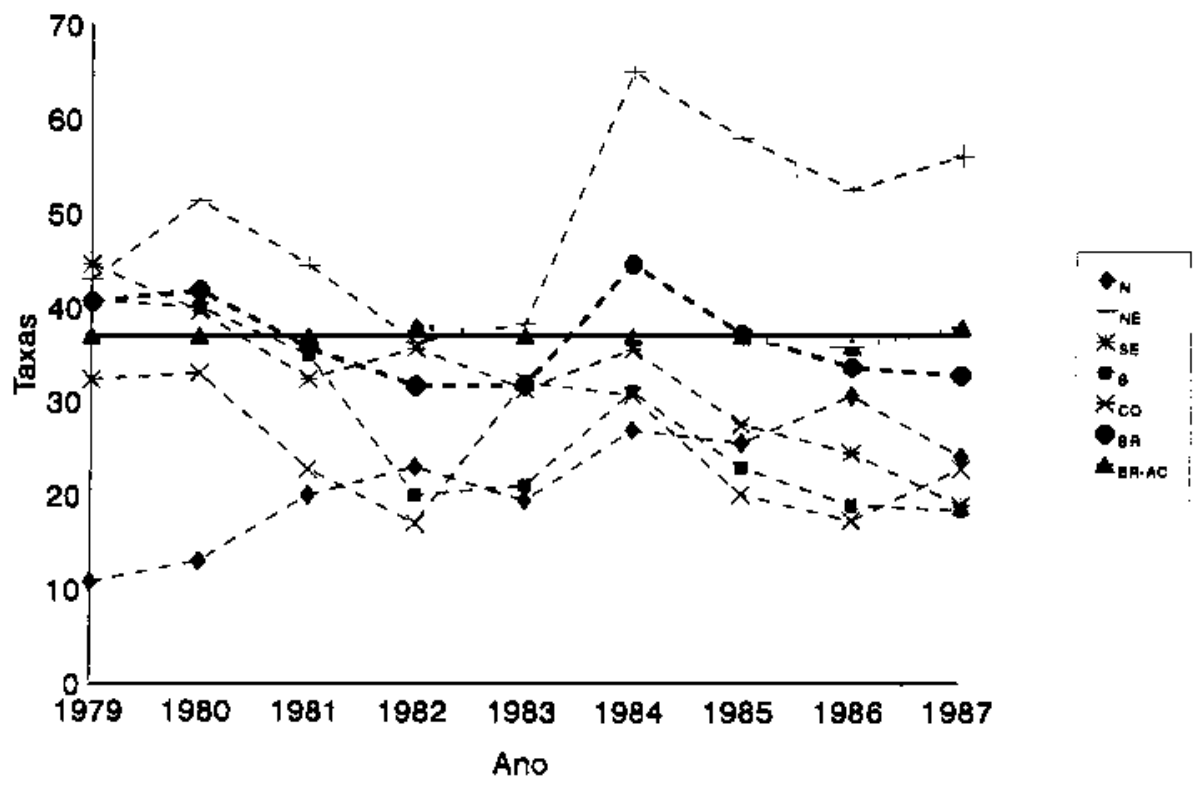

Figura 2 - Mortalidade infantil (/10.000 NV) por deficiências nutricionais, segundo grande regiāo e por anomalias congênitas (AC). Brasil. 1979-1987. 
(Szwarcwald ${ }^{41}$, 1993) e possibilitaram identificar os reflexos da crise econômica na população menor de um ano em diferentes áreas do território nacional.

Os achados mostraram consistência ao comportamento esperado para uma fase de desiquilibrio econômico. Apesar da tendência geral de descenso entre 1979 e 1989 , todas as regiões analisadas, apresentando variados contextos sociais e econômicos, demonstraram reprodutibilidade dos resultados: interrup̧̧ões na tendência de declínio da mortalidade infantil no ínicio dos anos 80 . Os aumentos foram associados ao componente tardio, sobretudo às doenças relacionadas à fome e à miséria como as diartéias e as deficiências nutricionais. Constatouse, ainda, que o excesso de mortes esteve conelacionado negativamente ao nível socioeconômico, sendo mais significativo nas regiōes de menor desenvolvimento, Norte e Nordeste.

O comportamento geral de declínio da mortalidade infantil, nos anos 80 , pode ser explicada, fundamentalmente pelas intermediaçōes do processo de urbanização da população que acabou por facilitar o acesso às ações e programas de saúde, à assistência médica e ao abastecimento de água encanada, além do impacto produzido pela queda contínua da fecundidade desde a década anterior. Por outro lado, desacelerações nos gradientes de declive, ao lado de picos de acréscimo, são interpretadas como prováveis decorrências do referido desequilíbrio econômico registrado nesse período.

Entre todas as dimensões da problemática da mortalidade infantil no Brasil, ficou fortemente evidenciada a disparidade espacial no sentido Norte-Sul. Enquanto o Centro-Sul demonstra sinais de similaridade aos níveis dos países desenvolvidos, a mortalidade infantil no Nordeste ainda é decrita por um padrão muito distante. $O$ perfil de mortalidade entre os menores de um ano na Regiāo Nordeste aportou para a carência de assistência médica, com elevado percentual de óbitos sem definição da causa básica, para a desnutrição e falta de saneamento básico, com relevante proporção de mortes por diarréia.

Embora não se tenha estabelecido ainda nenhuma situação de aclive contínuo, a constatacâo empírica das flutuações encontradas na série temporal estudada sugere a hipotese de uma teia de causalidade, onde as condições de vida, determinadas pelas variações na economia interagem com os benefícios da transição urbano-industrial da sociedade. Os efeitos negativos, desencadeados pelo agravamento da pobreza, são, certamente, contrabalançados pelos efeitos intermediadores como a implementacão de políticas sociais e de infra-estrutura urbana ao lado dos programas de prevenção e controle de doenças, acarretando em alterações na velocidade de decréscimo que estabelecem a não-uniformidade do processo de queda.

Desnecessário insistir que estas explicações podem não passar de meras especulações sugeridas pela instabilidade no padrão de declive repetidamente observada nas mais diferentes regiões analisadas. Evidentemente, outras hipóteses podem ser pertinentes para interpretar as flutuações observadas, como até mesmo, a de serem resultantes de simples aleatoriedade dos processos temporais.

Em suma, a análise demonstrou que a série temporal que descreve a evoluçăo da mortalidade infantil no Brasil nos anos 80 é marcada por nítidas interrupcōes na tendência de declínio. Afetada particularmente nas regiōes menos favorecidas, onde os aumentos foram atribuídos sobretudo às doenças relacionadas à subnutriçāo, o estudo revelou a persistência e a acentuação das desigualdades no processo de morte entre os menores de um ano.

\section{Referências Blbliográficas}

1. BANCO MCNDLAL. Relatório sobre o desenvolvimento mundial. Rio de Janeiro, Fundação Getúlio Vargas, 1991.

2. BECKER, R. A. \& LECHTIG, A. Brasil: evolução da montalidade infantil no periodo 1977-1984. Brasilia, Centro de Documentação do Ministério da Saúde, 1986. (Série C: Estudos e Projetos, 3).

3. BRASS, W. Metbods for estimating fertility and mortality from limited and defective data. Chapel Hill, Carolina Population Center, University of North Carolina, 1975.

4. CARVALHO, M.L et al. Concordância na determinação da causa básica de óbito em menores de um ano na Região Metropolitana do Rio de Janeiro. Rev. Saúde Pública, 24: 20-7, 1986.

5. CASTILHO, E.A, \& SZWARCWALD, C.L. Crise econômica: o impacto na montalidade. Rio de Janeiro, FIOCRL'Z, 1986.

6. FUNDAÇÃO IBGE. Anuário estatístico do Brasil - 1983. Rio de Janeiro, 1984.

7. FUNDAÇA IBGE. Estatisticas do registro civil: 1979. Rio de Janeiro, 1981. v. 6.

8. FUNDACÃO IBGE. Estatisticas do registro civit: 1980. Rio de Janeiro, 1981a. v. 7.

9. FLNDAÇÃO IBGE. Estatísticas do registro civil: 1981. Rio de Janeiro, 1983, v.8.

10. FLNDAÇÃO IBGE. Estatísticas do registro civi: 1982. Rio de janeiro, 1983a. v. 9.

11. FUNDAÇẢO IBGE. Estatisticas do registro civil: 1983. Rio de Janeiro, 1984. v, 10.

12. FUNDAÇÃO IBGE, Estatisticas do registro civil: 1984. Rio de Janeiro, 1986. 
13. FLNDAÇÀO IBGE. Estatisticas do registro civill: 1985. Rio de Janeiro, 1985. v. 12.

14. FUNDAÇÃO IBGE. Estatísticas do registro civil. 1986. Rio de Janeiro, 1988. v. 13.

15. FUNDAÇÃO IBGE. Estatísticas do registro civil: 1987. Rio de Janeiro, 1989. v, 14

16. FLNDAÇÃO IBGE, Estatísticas do registro civil: 1988. Rio de Janeiro, 1990. v. 15.

17. FUNDAÇÄO IBGE. Estatísticas do registro civil: 1989. Rio de Janeiro, 1991. v. 16.

18. GIRALDELLI, B.W. \& FERNANDES, D.M. Lma alternativa de estudo da interação entre mortalidade e economia. In: Encontro Nacional da Associacão Brasileira de Estudos Populacionais, 5ㅁ, Sào Paulo, 1986 Anais. Sào Paulo, ABEP, 1986 p.461-82.

19. GREEN, P.E. Analysing multivariate data. Hinsdale, The Dryden Press, 1978.

20. GUEDES J.S. \& GLEDES, M.S. Quantificacào do indicador de Nelson de Moraes (curva de mortalidade proporcional). Rev. Saúde Pública, 7: 103-13, 1973.

21. HAVOLLWKA, H.E. Measuring the health status of a population: current state of the art. Popul. Bull. United Nations, 23/24: 56-75, 1987

22. IRWIN, \& OLIVEIRA, L.A.P. Tendências e possibilidades na coleta de estatísticas vitais no Brasil. Rez! Bras. Estat, 35: 179-202, 1974.

23. JORGE, M.H.P.M. Sub-registro dos eventos vitais. Rev. Satide Pública, 17: 148-51, 1983.

24. LALRENTI, R. et al. Estatísticas de Saúde. Sào Paulo, Editora Pedagógica e Lniversitária, 1985.

25. MACEDO, R. Brazilian children and the economic crisis: the evidence from the state of São Paulo revisited. São Paulo, s.d.

26. MINISTÉRIO DA SAÚDE. Estatísticas de montalidade: Brasil, 1979. Brasilia, Centro de Documentação do Miniștério da Saúde, 1982.

27. MINISTÉRIO DA SAUUDE. Estatísticas de montalidade: Brasil. 1980. Brasília, Centro de Documentação do Ministério da Saúde, 1983.

28. MINISTÉRIO DA SAĹDE. Estatísticas de mortalidade: Brasil 1981. Brasília, Centro de Documentação do Ministério da Saúde, 1984.

29. MINISTÉRIO DA SAÚDE. Estatisticas de mortalidade: Brasil, 1982. Brasília, Centro de Documentação do Ministério da Saúde, 1985.

30. MINISTÉRIO DA SAĆDE. Estatisticas de mortalidade: Brasil, 1983. Brasília, Centro de Documentaçào do Ministério da Saúde, 1987

31. MINISTÉRIO DA SAĆDE. Estatísticas de mortalidade: Brasil, 1984. Brasilia, Centro de Documentaçào do Ministério da Saúde, 1987.
32. MIXISTÉRIO DA SAÚDE. Estatísticas de montalidade: Brasil, 1985. Brasília, Centro de Documentação do Ministério da Saúde, 1988.

33. MINISTÉRIO DA SAÚDE. Estatisticas de montalidade: Brasil. 1986. Brasília, Centro de Documentação do Ministério da Saúde, 1991.

34. MINISTÉRIO DA SAÚDE. Estatísticas de mortalidade: Brasil, 1987. Brasilia, Centro de Documentaçào do Ministério da Saúde. 1992.

35. MORAES, N.L.A. Niveis de saúde de coletividades brasileiras. Rev: Sern'. Satide Pública, 10: $403-97,1959$.

36. OLIVEIRA, L.A.P. A mortalidade infantil e a dinâmica social. In: Simòes, C.C.S. org. Perfil estatistico de crianças e màes no Brasil: mortalidade infantil e saúde na década de 80 . Rio de Janeiro, Fundação IBGE, 1989. p.49-54.

37. POLlaRD, A.H. et al. Demograpbic tecbniques. Sidney. Pergamon Press, 1974.

38. SAWYER, D.O. Consideraçóes sobre o estudo de mortalidade na América Latina (versào revisada). México, Population Council, 1984. (Documento de Trabalho n. 18).

39. SIMÒES, C,C.S Novas estimativas da mortalidade infantil-1980/87. In: Simòes, C.C.S. org. Perfil estatistico de crianças e màes no Brasil: mortalidade infantil e saúde na década de 80. Rio de Janeiro, Fundação IBGE, 1989. p.14-48

40. SIMÒES, C.C.S. \& OLIVEIRA, L.A.P. Evolução da mortalidade infantil. In: Fundaçào IBGE. Perfil estatistico de crianças e mães no Brasil: aspectos socioeconómicos da monalidade infantil em áneas urbanas. Rio de Janeiro, 1986. p.29-48.

41. SZWARCWALD, C.L. Estimativas da mortalidade infantil como funçào da distribuição etária dos óbitos registrados: proposta de um procedimento. [Tese de Doutorado. Rio de Janeiro. Escola Vacional de Saúde Pública. FIOCRLZ].

42. SZWARCWALD, C.L. et al. Características da mortalidade no Estado do Rio de Janeiro 77 a 86. In: Simòes, C.C.S. org. Perfil estatístico de crianças e mảes no Brasit: mortalidade infantil e saúde na década de 80 . Rio de Janeiro, Fundação IBGE, 1989. p.91-102.

43. LXITED NATIOXS. Model life tables for developing countries. New York, 1982. (Population Studies $\mathrm{N}, 77$ ).

44. LNITED NATIONS. Mantual $X$ : indirect tecbniques for demographic estimation. New York, 1983. (Population Studies X. 77).

45. LNITED NATIONS. Step-by-step guide to the estimation of cbild mortality. New York. 1990 (Population Studies . N.107).

\begin{abstract}
A procedure for the estimation of the infant mortality rate in Brazll, in the 1980's, based only on the age distribution of registered deaths, is here proposed. Using this technique, it is possibie to estimate the probabilities of dying in the first year of life in a continuous way, year by year, for different regions of the country. The space-time distribution of the main causes of infant deaths is analysed and the relevance of using this coefficient to express the social and economic conditions of the Brazilian population from 1979 to 1989 is discussed.
\end{abstract}

Infant mortality, trends. Cause of death. Estimation techniques. 


\section{Anexo}

Com o objetivo de construir modelos de mortalidade específicos para populações subdesenvolvidas, o projeto das Naçōes Unidas ${ }^{43}$, (1982) consistiu em analisar um conjunto de tábuas de vida de diferentes países da América Latina, Ásia e África, traduzidas matematicamente pelos logitos das probabilidades de morte (logito $\left.{ }_{n} \mathrm{q}_{\mathrm{x}}\right)^{*}$ nos grupos etários $0-1,1-4, \ldots ., 80-84$.

O modelo geral da ONU baseou-se em estabelecer que variaçőes na estrutura etária da mortalidade de uma populacão em relação à outra, tomada como padrão, são expressas por meio de uma regressão linear, resultante de uma análise estatística por componentes principais. Considerando-se dois componentes, o modelo geral da ONU é descrito por:

$$
\text { (A1) logito }{ }_{n} q_{x}-\operatorname{logito}_{n} \bar{q}_{x}=b_{1} u_{1 x}+b_{2} u_{2 x}
$$

onde ${ }_{n} \mathfrak{q}_{x}$ e ${ }_{n} \bar{q}_{x}$ são, respectivamente, as probalidades de morrer entre as idades $x$ e $x+n$ da população em estudo e da população padrăo, $u_{1 x}$ e $u_{2 x}$ coordenadas dos dois primeiros componentes apresentados na referida publicação - e $b_{1}$ e $b_{2}$ parâmetros a serem estimados por procedimentos de regressão.

Após a estimação dos coeficientes da regressão, são determinados os valores ajustados das probabilidades de morte. Observa-se, porém, que se em uma determinada população existe expressivo sub-registro de óbitos em todas as faixas etárias, a aplicação direta do procedimento produz estimativas incorretas dos parâmetros do modelo e, em decorrência, ajustes incorretos das probabilidades de morte.

Com o propósito de incluir parâmetros no modelo que representassem o sub-registro de obitos por grupo etário, por meio de transformaçôes matemáticas das funçōes da tábua de vida, reformulou-se o modelo geral da ONU, possibilitando descrever os logaritmos das taxas específicas de mortalidade por uma regressão linear:

$$
\begin{gathered}
\text { (A2) } \frac{1}{2}\left\{\log _{n} m_{x}-\log _{n} \bar{m}_{x}\right\} \cong b_{1} u^{*}{ }_{1}+b_{2} u^{*}{ }_{2} \text {, onde, } \\
u^{*}{ }_{i x}=u_{i x}\left(1-{ }_{n} a_{x}{ }_{n} \bar{m}_{x}\right)
\end{gathered}
$$

$\mathrm{n}^{\mathrm{a}} \mathrm{x}$ é o número médio de anos vividos entre as idade $\mathrm{x}$ e $\mathrm{x}+\mathrm{n}, \mathrm{e}_{\mathrm{n}} \mathrm{m}_{\mathrm{x}} \mathrm{e}_{\mathrm{n}} \overline{\mathrm{m}}_{\mathrm{x}}$ såo, respectivamente, as taxas centrais de mortalidade da população em estudo e da população padrảo.

Por outro lado, representando-se a cobertura dos b́bitos registrados no intervalo etário $(x, x+n)$ por ${ }_{n} S_{x}$, tem-se:

$$
\text { (A3) }{ }_{n} m^{\prime}{ }_{x}={ }_{n} m_{x} \cdot{ }_{n} S_{x}
$$

onde ${ }_{n} m^{\prime}{ }_{x}$ são as taxas centrais de mortalidade calculadas a partir das informações de registro $e_{n} m_{x} s a ̃ o$ as verdadeiras taxas.

Substituindo-se a igualdade (A3) no modelo (A2), obtém-şe a equação geral do modelo da ONU modificado, denominado de "MONUM":

$$
\text { (A4) } \frac{1}{2} \log _{n} m^{\prime}{ }_{x}-\frac{1}{2} \log _{n} \bar{m}_{x} \cong \frac{1}{2} \log _{n} S_{x}+b_{1} u^{*}{ }_{1}+b_{2} u^{*}{ }_{2} \text {. }
$$

Propondo adequados modelos para descrever o comportamento da cobertura ${ }_{n} s_{x}$ por idade, os coeficientes $b_{j}$ são estimados para produzir o melhor ajuste à regressão (A4), possibilitando determinar as funções da tábua de vida.

* logito ${ }_{n} q_{x}=0.5 \log \ln _{n} q_{x}\left(\left(l_{n} q_{x}\right)\right)$, onde ${ }_{n} q_{x}$ é a probabilidade de morrer entre as idades $x$ e $x+n$. 
Admitindo-se sub-registro aproximadamente invariante em um certo intervalo etário (e.g. 1-69 anos), isto é, ${ }_{n} S_{x}=s$, obtém-se um modelo linear:

$$
\text { (A5) } \begin{gathered}
\frac{1}{2} \log _{n} m_{x}-\frac{1}{2} \log _{n} \bar{m}_{x} \cong b_{0}+b_{1} u_{1}^{*}+b_{2} u_{2}^{*} \text {, onde, } \\
b_{0}=\frac{1}{2} \text { logs. }
\end{gathered}
$$

Neste caso, a cobertura constante s é determinada pelo valor estimado do coeficiente linear da regressāo. 